\title{
Assessment of the environmental aspect of corporate sustainability of companies
}

\author{
E.S. Blinova*, and T.V. Ponomarenko \\ St. Petersburg Mining University, Vasilievsky Island, 21 line 2, 199106 St. Petersburg, Russia
}

\begin{abstract}
Strengthening international environmental and climate policies dictates a reorientation of companies towards corporate sustainability management. The article discusses the issues of assessing the environmental performance of companies in the context of corporate sustainability. The main methods of assessing the environmental aspect of corporate sustainability have been analyzed. The classification of the main methods for assessing the corporate sustainability has been presented. The application of methods for assessing the dynamics of environmental indicators of corporate sustainability of companies, including mining companies, has been substantiated. Mining companies have been proven to cause significant damage to the surrounding ecosystems. The use of indicators of economic impact and environmental and economic assessment has been substantiated.
\end{abstract}

\section{Introduction}

The development of Russian business as a whole corresponds to the global trend of business transformation in the interests of sustainable development and the formation of models of corporate sustainability [1].

Global trends in the development of international communities show that the management of companies is aimed at increasing the corporate sustainability. The corporate sustainability is inextricably linked to both sustainable development and corporate social responsibility. In this regard, when managing the corporate sustainability, such spheres of the company's functioning as ecology, economy and society are singled out and evaluated [2-3].

To date, there is still no single approach to the definition of "corporate sustainability". This fact predetermines the fact that there are no uniform criteria that reflect the development of the company in the field of ecology, economy and society. This article will consider approaches to assessing the environmental aspect of the corporate sustainability, since the tightening of environmental and climate legislation will actualize environmental requirements for activities even more.

Analysis of methods for assessing the environmental aspect of the corporate sustainability has shown that all existing assessment methods can be conditionally divided into several groups:

- individual indicators of environmental impact,

"Corresponding author: ekblinova@icloud.com 
- economic and environmental indicators,

- environmental indexes.

The importance of assessing the corporate sustainability for mining companies is determined by the specifics and strength of their impact on the environment, including: greenhouse gas emissions, pollution of natural water bodies, deforestation, soil pollution, dehydration and salinization of the soil layer. Therefore, the companies are faced with the need to implement the environmental projects that create social capital. It is understood as the development and implementation of the strategies for environmental safety, allowing to increase confidence on the part of counterparties and stakeholders of the company [4-5].

The environmental assessment of corporate sustainability has several objectives:

1) assessment of the dynamics of environmental indicators to identify the effectiveness of the adopted management decisions;

2) benchmarking to compare the companies with similar business models to identify the best technologies and their possible use.

The aim of the study is to substantiate the selection of the method for assessing the environmental aspect for mining companies.

The research objectives are:

- review of existing assessment methods,

- $\quad$ systematization and analysis of the methods,

- $\quad$ analysis of the applicability of valuation methods for mining companies

\section{Methodology}

The article used the method of analysis and systematization of existing methods for assessing the environmental aspect of corporate sustainability.

The analysis of the scientific literature related to the concept of corporate sustainability has shown a different understanding of this category. In this regard, the need to assess the environmental aspect is also understood differently. Three approaches to the definition of the corporate sustainability have been identified.

The first approach equates the sustainable development with the corporate sustainability. An assessment of the environmental aspect in this approach is necessary; without increasing the environmental sustainability, it is impossible to increase the corporate sustainability. But this approach does not define the environmental aspect as the main one, since the enterprise should equally increase economic sustainability, production, marketing, and organizational and develop comprehensively in all industries [6-8].

The second approach to the definition of the corporate sustainability equates it with the corporate social responsibility. And in this approach, environmental development is key, but not the main one [9-10].

The third approach defines the corporate sustainability in terms of competitiveness and profit growth. The preservation of ecosystems, reduction of the impact on climate change is of secondary importance.

None of the approaches emphasizes the need to assess the environmental aspect, since all the approaches assume the presence of many factors that determine the corporate sustainability [11-12].

Identifying the individual indicators of environmental health and results is the simplest method for determining the dynamics of the corporate sustainability. It is easy for the company's management to identify key indicators of the environmental development, taking into account the specifics of production. The same indicators are reflected in the non-financial statements of companies. For the industries of the mineral resource sector (MRS), among the individual indicators of interaction with the environment, one can single out [13]: 
- indicators that characterize water consumption,

- indicators that characterize energy consumption,

- indicators that characterize the use of waste,

- indicators that characterize the reduction of emissions and other indicators that characterize resource consumption.

In the companies of the mineral resource sector (MRS), these indicators are widespread and are used as representative indicators of the dynamics of the environmental sustainability. At the same time, MKS companies have different scales of activity, and with an increase in capacity, the absolute values of pollution, emissions and waste will grow. All this creates a contradiction according to which only small companies in the industry will be more environmentally sustainable. This factor makes the assessment of the environmental aspect of the corporate sustainability of MKS companies by the methods of the first group in terms of final indicators not fully objective, in terms of specific indicators it is also difficult to compare.

It is easy to measure and monitor the dynamics of individual environmental indicators, therefore, it is possible to assess the effectiveness and efficiency of measures aimed at achieving the values of the set indicators.

The complexity is added by the need to separate indicators of production efficiency (they were discussed above) and indicators of management efficiency.

Some authors highlight the following criteria for achieving the corporate sustainability in the field of ecology:

- environmental policy,

- environmental (social, integrated) reporting,

- company's management system (environmental management) [13].

Without the development of management performance indicators, the development of production is impossible, since the company needs a regulatory framework to implement any projects. There are examples of evaluating managerial efficiency, for example, in Gazprom company. At the same time, they are largely of an evaluative nature, which complicates the possibility of their correct application. It is impossible to independently assess the indicators of management efficiency, because the final indicators are the indicators of production efficiency. In addition, the mere presence of functional environmental structures in companies does not allow assessing the quality of the environmental policy being implemented.

The second group of methods for assessing the environmental aspect of the corporate sustainability includes economic and environmental methods.

The essence of the methods lies in the fact that in addition to the positive effect of the introduction of environmental protection measures, the company receives an increase in the economic efficiency of the business entity. Thus, project appraisal influences the company's environmental sustainability assessment.

Based on the essence of these methods, the corporate sustainability of a company can be determined by the following criteria [14]:

- presence/absence of economic effect from the implementation of technologies in the field of energy and resource conservation,

- presence/absence of functional structures in the company that implement the environmental policy,

- dynamics of development/implementation of projects to protect the environment.

Within the framework of the 3 listed criteria, 10 indicators have been distinguished with weights established by an expert, namely:

- economic effect from the introduction of energy and resource saving technologies,

- coefficient of environmental pollution, 
- effectiveness of environmental protection measures,

- utilization rate of secondary raw materials,

- waste utilization rate,

- availability and functioning of functional structures for environmental management in companies,

- reduction amount of the environmental fees,

- development and implementation of R\&D projects in the field of the environment,

- implementation of separate collection of industrial waste,

- $\quad$ organization of safe storage of industrial waste[14].

All values of the indicators are multiplied by their weight coefficients for each parameter, after summing up, a complex indicator of sustainable environmental development is obtained. This coefficient is intended to assess the dynamics of the environmental aspect of the corporate sustainability within a single enterprise. The advantages of the index include the simplicity of calculation; the calculation of the coefficient for the enterprises of the industry will be able to distribute enterprises according to the levels of environmental development. The disadvantage of the method is its subjective nature, represented by the expert definition of the authors of the method of weight values and a set of indicators [15-17].

The proposed methodology raises doubts, since the criteria, indicators for assessing the ecological state, and their weight values are not regulated. There are also environmental and economic indicators that are not comprehensive, but reflect the economic effect of the introduction of the environmental protection measures. These assessment methods include the dynamics of the magnitude of the environmental impact. The indicator is the sum of the average values of payments for the negative impact on the environment (including possible penalties), taxes on the use of minerals, the costs of maintaining the operation of dustcollecting and treatment plants, waste disposal, depending on the type of environmental impact.

The third group of indicators that assess the environmental aspect of corporate sustainability include the environmental indices. Basically, all indices assess the corporate sustainability in general, that is, they can be considered broad-based indices focused on assessing the environment, economy and society. For example, such indices include: Dow Jones Sustainability World Enlarged Index, MSCIEAFEESG Index, FTSE4Good Europe Benchmark Index, NASDAQ OMX CRD, etc. It is not possible to evaluate exclusively the ecological aspect according to the listed indices [18-19].

The environmental aspect of the sustainable development is assessed only by a few indices, among which the NERAX-Eco and the FTSE CDP Carbon Strategy 350 Index can be distinguished.

The NERAX-Eco Index was developed by the Independent Environmental Rating Agency (NERA). The assessment is based on a number of indicators that assess the resource and energy efficiency of companies, as well as their fundamental and technological components [18-19]. The developers do not provide an evaluation mechanism in detail, since this information is intellectual property, the principal evaluation mechanism is as follows.

There are two groups of companies on the Russian market:

- the best companies in the field of environmental production efficiency,

- the best of the company's progress to reduce the impact on the environment.

Among the most liquid issuers, stocks of companies included in the rating of social and economic responsibility are selected, then $20 \%$ of companies are selected from this list, which are the leaders in the two directions presented above. An additional condition for getting into the list of leading companies is the provision of transparent social and environmental reporting. 
Next, the average price level is calculated (using capitalization as the basis for the weighting factors). The resulting value is divided by a fixed coefficient, which is selected in such a way as to get $100 \%$ at the initial moment of calculating the index. Companies that fall into 2 categories at the same time have double weight in the index.

Such an assessment system allows one to determine the internal problems of the company's management, since the environmental efficiency of production and the rate of its change reflect the success or failure of technical and managerial modernization.

Although the NERA methodology assesses the environmental component of production, it nevertheless links it to the economic activity of the company, and ultimately serves as an indicator for assessing the investment risks. According to the authors of the methodology, environmental indices are more objective in determining the corporate sustainability, since, unlike financial statements, they cannot be adjusted [20]. There are examples when environmental indices showed negative company dynamics, while companies were stable in terms of financial performance. For example, YUKOS, assessed by NERA ratings, had internal problems from 2000-2003. This was unexpected for foreign partners when they had to deal with technical and environmental problems associated with the acquisition of the company.

FTSECDP Carbon Strategy 350 Index assesses the climate change and greenhouse gas emissions. The research methodology is not explained, since it is intellectual property, in principle, the mechanism is as follows.

The company sends out questionnaires to the world's largest corporations (today the pool includes about 3,700 companies). The content of the questionnaire is focused on collecting information on climate change, the level of emissions in companies, the risks and opportunities of companies to manage climate change, as well as the environmental management system. After processing the questionnaires, companies are assigned the points for good environmental strategy management [18-19].

The dynamics of this index shows the extent to which companies are ready to implement measures to reduce the emissions, to comply with the tightening international climate policy, to reduce the risks of climate change.

This index can be considered the most relevant for companies that emit greenhouse gases, primarily for the companies in the fuel and energy complex. For the companies in other industries, the FTSECDP Carbon Strategy 350 Index will be unrepresentative.

\section{Results and discussion}

The review of assessment methods allows you to systematize the methods that are designed to determine the level of environmental development of the companies within the framework of the corporate sustainability (Figure 1). 


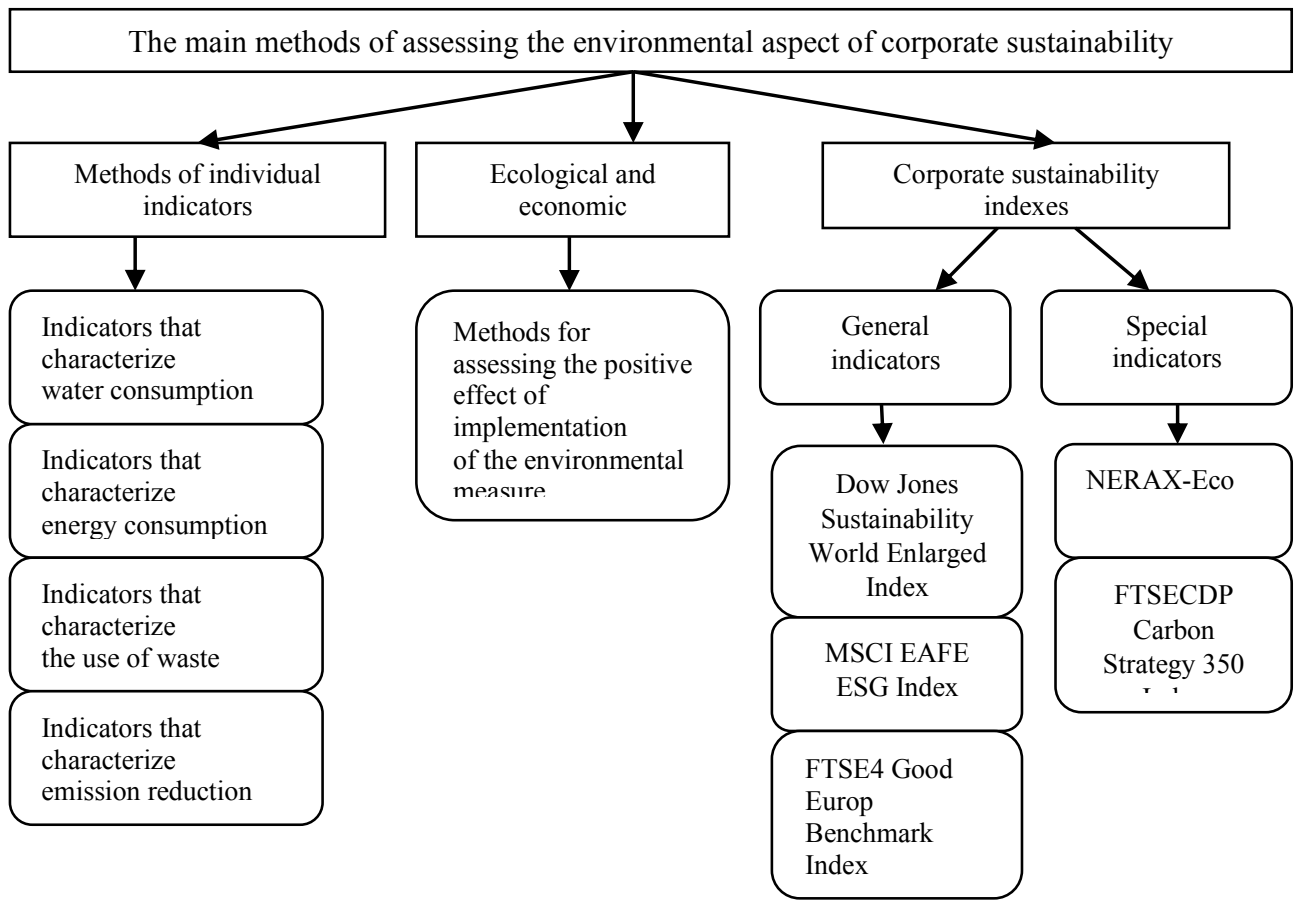

Fig. 1. Systematization of the main methods for assessing the environmental aspect in the corporate sustainability.

Based on the analysis, Figure 2 was compiled, which identifies the main advantages and disadvantages of assessment methods.

Advantages and disadvantages of methods for assessing the environmental aspect of the
corporate sustainability

Fig.2. Advantages and disadvantages of methods for assessing the environmental aspect of the corporate sustainability.

In our opinion, among the methods considered, there is no assessment system that would give an objective understanding of the level of the environmental sustainability of 
the companies in the mineral resource complex. In this regard, a combination of methods is necessary.

The methods of the first group should be used primarily for the development of performance indicators of the environmental strategies and the environmental programs when evaluating the environmental protection projects in mining companies. The developed system of indicators should be based on an integrated approach to assessing the environmental sustainability. Firstly, to take into account the production indicators for the environmental performance, and secondly, to assess the quality of the environmental management in the companies.

Comparison of the companies with similar business models in terms of the indicators of the first group is permissible, but does not take into account the specifics of the mining and geological conditions of the deposits, as well as the mining technical factors of operation. For example, a deep ore body will increase the overall level of production waste compared to mineral deposits at shallow depths.

The existing methods for assessing the environmental aspect of the corporate sustainability using the environmental and economic methods are also partially applicable for MRS companies. Among them, only methods that take into account the indirect economic effect from the introduction of the environmental projects are applicable, since their implementation should not be aimed at increasing the production efficiency.

The second group of indicators also does not take into account the peculiarities of mineral deposits. For example, there is a difference in the gas content of coal mines even within the same field. Accordingly, this group of indicators is applicable only to assess the dynamics of the environmental sustainability within one company, and sometimes even within the same field.

It is impossible to provide an objective assessment of the methods of the third group, since no methodology is disclosed in detail. These methods are focused on the analysis of the largest companies. Small and medium-sized businesses will not be included in the sample, and their cumulative impact on the environment, including climate change, may be large and need to be assessed. In this group of methods, the specific characteristics of the mining company's mineral deposits are not taken into account.

\section{Conclusion}

The main conclusions of the study include:

1. To date, there is no unified approach to assessing the environmental aspect of the corporate sustainability of the companies in any type of economic activity, including the mineral resources sector.

2. Assessment of the environmental aspect of the corporate sustainability in almost all analyzed methods is linked with the financial results of the company or with the economic effect of the introduction of the environmental protection measures.

3. Each assessment method has advantages and disadvantages. Among the main disadvantage of all methods, one can single out the lack of a universal method used for different industries and scales. In this regard, the management of the company must independently reasonably choose a methodology to identify the dynamics of the assessment of the environmental aspect within the framework of the corporate sustainability, taking into account the specifics of the company.

4. For the companies of the mineral resource complex, it is most expedient to use the methods of individual indicators, as well as some of the environmental and economic methods. However, neither the first nor the second group of methods takes into account the specifics of the characteristics of the companies' fields. In this regard, the use of 
benchmarking is impossible, the development and analysis of indicators for assessing the environmental aspect of the corporate sustainability is necessary for management.

\section{Acknowledgment}

The study has been carried out with the financial support of the Russian Foundation for Basic Research and the Ministry of Culture, Education, Science and Sports of Mongolia in the framework of the scientific project No. 19-510-44013\19.

\section{References}

1. K.Yu. Belousov, Problems of modern economy, 120 (2012)

2. T. A. Pikalova., N.V. Smirnova, Albena: International Multidisciplinary Scientific Geoconference, The development of methods for assessing the level of sustainable development of mining company, 3, 629 (2015)

3. T. V. Ponomarenko., M. A. Nevskaya, O.A. Marinina, Sustainability (Switzerland), 12, 5582(2020)

4. V. A. Roerich, Science and education today, 3, 38 (2019)

5. Website of the international consulting company Pricewaterhouse Coopers, https://www.pwc.ru

6. E.N. Kucherova, OSU Bulletin, 9, 76 (2007)

7. L. Lankoski, Journal of Cleaner Production,139, 847 (2016)

8. C.Villiers, Journal of Cleaner Production, 136, 78(2016)

9. W. Hediger, Journal Socio-Economics,39, 518 ( 2010)

10. I. Montiel, Organizational Environment,21, 245 (2008)

11. S.A. Panova, Russian entrepreneurship, 8,78 (2003)

12. R.Lozano, Corporate Social Responsibility Environmental Management, 22,.32 (2015)

13. I.Montiel, J.Delgado-Ceballos, Organization and Environment, 2, 1 (2014)

14. E.L. Zimina, D.K. Pankevich, S.M. Goryacheva, Bulletin of VSTU, 1, 128 (2019)

15. O. A. Marinina, IOP Conference Series: Earth and Environmental Science, 302, 1 (2019)

16. M.A. Nevskaya, O.A. Marinina, Research Journal of Pharmaceutical, Biological and Chemical Sciences, 7, 2352 (2016)

17. T.V Ponomarenko., R.P.Volnik, O.A.Marinina, Notes of the Mining Institute, 222, 882(2016)

18. A.V. Khoroshavin, Implementation of the sustainable development goals: European and Russian experience: collection of scientific articles based on conference materials, 184 (2019)

19. A.V. Khoroshavin, North Palmyra: collection of scientific papers of the IX Youth environmental conference. Saint Petersburg, 134 (2018)

20. V.V. Artyukhov, A.S. Martynov, Metodics of assessing the environmental and energy efficiency of the Russian economy (2010) 